\title{
Development of an Ultra Wide Band (UWB) Microwave Radar System for Foliage Penetrating Ground Detection in Wild Blueberry Fields
}

\author{
Muhammad Saad ${ }^{1}$, Qammar U. Zaman1, Travis J. Esau', Aitazaz A. Farooque ${ }^{2}$, Arnold W. Schumann ${ }^{3}$ \\ ${ }^{1}$ Department of Engineering, Dalhousie University, Truro, Canada \\ ${ }^{2}$ Department of Sustainable Design Engineering, University of Prince Edward Island, Charlottetown, Canada \\ ${ }^{3}$ Soil and Water Science Department, University of Florida, Gainesville, United States
}

\begin{abstract}
Wild blueberries (Vaccinium angustifolium Ait.) is a low shrub fruit crop native to northeastern North America. Mechanical harvesting has been proven as the most cost-effective method for picking wild blueberries. Harvest efficiency for wild blueberry mechanical harvesters depends on the operator's skill and full automation of picking heads rely on the accurate and precise determination of berry picking height. Spatial variation in wild blueberry fields creates a serious challenge for the operators to maintain the optimum head height for harvester operation. Variation in plant density throughout the crop fields requires a non-destructive foliage penetration ground detection technique to automate the harvester head height for optimum berry picking operation and to reduce operator stress. The aim of this research is to develop a non-destructive ground detection system using an ultrawideband microwave radar sensor for its application in wild blueberry fields. Two three dimensional sensors operating in ultrawideband frequency range selected for this study were; i) Terrahawk HT5230 (Headsight Inc., Bremen, Indiana, USA) with operating frequency bandwidth of 1.5-6.5 GHz, and ii) Walabot Developer Model (Walabot, Vayyar Imaging Ltd., Fairfield, USA) with frequency bandwidth of 3.3-10 GHz. Selected radar sensors are Frequency Modulated Continuous Wave radars, which transmit an electromagnetic signal continuously and frequency of this signal changes over time, generally in a sweep across a defined bandwidth. A single board development unit with a built-in microprocessor, laptop, customized software using Fast Fourier Transform (FFT) technique, and both sensors were mounted on electrically powered Specialized Farm Motorized Vehicle (SFMV) for field and lab evaluations. Two fields were selected in Debert, Nova Scotia, for carrying out the field trials to cover the maximum variability in plant characteristics. Linear regression and correlation analysis were performed to correlate the output of both sensors with manually measured ground surface height. Preliminary results revealed that the output of Terrahawk $\left(R^{2}=0.95\right)$ and Walabot $\left(R^{2}=0.72-0.79\right)$ radar sensors were significantly correlated with manual measurements. Further trials will be replicated in 2020 and statistical analysis will be performed accordingly to determine the performance efficiency, which will help in selecting the most suitable sensor for its application in ground detection. The expected outcome of this research is to successfully develop a system that can penetrate through the foliage in a non-destructive manner to detect the ground surface in low bush blueberry fields. The developed system will eventually aid the automation of the picker head for the wild blueberry mechanical harvester.
\end{abstract}

